\title{
DESIGN AUTOMATION FOR CUSTOMISED AND LARGE- SCALE ADDITIVE MANUFACTURING: A CASE STUDY ON CUSTOM KAYAKS
}

Lithgow, Drew (1); Morrison, Cara (1); Pexton, George (1); Panarotto, Massimo (2); Müller, Jakob R. (2); Almefelt, Lars (2); McLaren, Andrew (1)

1: University of Strathclyde; 2: Chalmers University of Technology

\begin{abstract}
Additive Manufacturing (AM) offers the potential to increase the ability to customise large-scale plastic components. However, a substantial amount of manual work is still required during the customisation process, both in design and manufacturing.

This paper looks into how the additive manufacturing of mass customised large-scale products can be supported. Data was collected through interaction with industrial partners and potential customers in a case study regarding the customisation of kayaks.

As a result, the paper proposes a model-based methodology which combines design automation with a user interface.

The results point to the benefit of the proposed methodology in terms of design efficiency, as well as in terms of displaying results to the end user in an understandable format.
\end{abstract}

Keywords: Additive Manufacturing, Design methods, Product modelling / models

Contact:

Panarotto, Massimo

Chalmers University of Technology

Industrial and Materials Science

Sweden

massimo.panarotto@chalmers.se

Cite this article: Lithgow, D., Morrison, C., Pexton, G., Panarotto, M., Müller, J.R., Almefelt, L., McLaren, A. (2019)

'Design Automation for Customised and Large-Scale Additive Manufacturing: A Case Study on Custom Kayaks', in Proceedings of the 22nd International Conference on Engineering Design (ICED19), Delft, The Netherlands, 5-8 August 2019. DOI:10.1017/dsi.2019.74 


\section{INTRODUCTION}

In the modern economy, there is a continually growing demand for both increased product variety and decreased delivery times (Mcutcheon et al., 1994). This has put a large pressure on industry to find solutions that allow them to meet their customers' needs and expectations while still maintaining a cost and time efficient production and design process. For this reason, manufacturers have recently shown interest in the use of additive manufacturing (AM) techniques - such as fused filament fabrication (FFF) - to provide mass customised products, since the costs and times associated to manufacturing are reduced (Spallek and Krause, 2016).

Despite the potential of using AM for mass customisation, a number of technical challenges exist. One example is the mechanical performance and the residual stresses of parts fabricated with FFF (Thompson $e t$ al., 2016). Therebeyond these, there are challenges related to the design process, which are particularly concerning for the manufacturers of large-scale products (i.e products with a size larger than $0.5 \mathrm{~m}^{3}$ ). These manufacturers are interested in using AM to extend their customer base through the offering of customised and cost-efficient products. However, the targeted new customers are likely to be non-designers, who often are not able to articulate their needs and expectations in the form of precise and measurable design requirements and features (Ulrich and Eppinger, 2011). The translation of customer needs and expectations into design features requires a substantial amount of manual work during design and production (Thompson et al., 2016).

This paper explores this challenge, focused on the following research question: 'How can the rapid manipulation of customer needs and design features be supported - in the context of additive manufacturing of mass customised large-scale products?'

This paper aims to outline a methodology to support the design and visualisation of mass customised and large-scale plastic products, by incorporating three key elements: knowledge-based engineering, design automation (DA) and mass customisation.

\section{RESEARCH METHODOLOGY}

This paper aims to support the design of large-scale customised plastic products. This study uses an action research approach to determine whether integrating KBE and DA for an additively manufactured product can achieve this. Action research is a qualitative systems approach which encourages researchers to try their theory within a real-life scenario to gain feedback and is particularly suitable in cases where there is no pre-defined solution (Avison et al., 1999).

This study falls within a larger project, aiming to support the design of large-scale plastic products using $\mathrm{AM}$, with the objective to increase production flexibility and enable a quicker time-to-market. The project features 16 partners, out of which 14 are industrial partners. The case study selected involves the design of customised and additively manufactured kayaks. This decision was made on the basis that kayaks are an suitable for customisation because they need to suit the environment of use, the experience level of the kayaker and anthropometric measurements of the user.

Customer mapping was carried out through literature research which was validated by the Chairman of the Regional Development Centre for Professional Kayakers in Gothenburg. A kayak designer that currently offers customised kayaks was also sought out and interviewed to gain a greater understanding of the current challenges faced and the timescales that are currently achievable. The final proposal was then presented to 10 of the project partners at a meeting and their feedback was gathered in the form of a survey. The project partners include a Swedish research institute investigating large scale AM, suppliers of AM equipment and a Swedish based kayak company. This ensured that the feedback was obtained from a diverse audience allowing many different perspectives to be accounted for.

\section{LITERATURE REVIEW}

The literature review is split into the respective three sub-sections: Section 3.1 looks at the needs and challenges that arise when considering AM for customisation, with section 3.2 describing the challenges of mass-customisation and section 3.3 investigating the benefits of DA. 


\subsection{Additive manufacturing as a means for customisability}

The use of AM allows for the production of smaller batch sizes with individual designs in an economical fashion (Spallek and Krause, 2016). This makes it a process suitable for mass customisation, as it does not add any extra tooling. This contrasts with traditional manufacturing, which would require a costly and timeconsuming creation of custom moulds, tools or processes for the new product, before setup and manufacture of each new product (Reeves et al., 2011), thereby enabling make-to-order or even engineerto-order products. This has better potential (in terms of time and cost effiency) than standard make-to-stock approaches where products are already stocked in inventory as finished goods or quickly assembled from in-stock components (Mcutcheon et al., 1994).

However, while bearing all these benefits, the development of methods to design for AM (DfAM) is still under development (Lindwall, Dordlofva and Öhrwall Rönnbäck, 2017). Two major design approaches have emerged: opportunity driven, i.e. explicitly making use of the novel design freedom that DfAM provides (Campbell, Bourell and Gibson, 2012) and manufacturing driven approaches, which focus on adapting existing designs to be manufacturable using AM (Thompson et al., 2016). In this study, the second approach is followed, where traditional kayak design-elements are adapted to the new manufacturing technology.

\subsection{The challenges of mass-customisation}

While the need for mass-customised products is rising, the market mainly provides still mass-produced products, due to the limitations of conventional manufacturing and design methods (Hvam et al., 2008).

The actual customisation can be done on different levels, such as providing different modules of varying functionality which can be combined by the customer (Roth et al., 2016). However, for highly integrated products (such as a kayak, which is composed of only one module) this approach is not appropriate. One approach to this is the mapping of engineering characteristics of the product towards identified product values on different levels (Bertoni et al., 2013; Panarotto, 2015). Other methods approach the customisation via the product's functionality (Borgue et al., 2018), where a function model is used to adapt a product for AM.

A critical challenge in mass customisation is the interface between the company and the customer, as it acts as the core communication tool. This is particularly essential in customisation as often users have no clear knowledge of which solution may correspond to their requirements (Franke and Piller, 2003). Dellaert and Dabholkar (2009) demonstrated that offering product visualisation results in an increased cost-benefit perception for consumers. Creating a successful interaction enables the user to co-create a unique experience, which is highlighted as another approach for creating competitive advantage (Prahalad and Ramaswamy, 2004).

There are two factors which control the user experience on a technology-based self-service experience; perceived control and perceived enjoyment. Perceived control is defined as the extent to which the consumer believes they can control the outcome of the customisation process and perceived enjoyment is the customers perceived pleasure associated with the customisation experience. Perceived control can be increased by offering additional customisable options and perceived enjoyment can arise from the pleasure of an interactive technology experience and creating an outcome based on their ideal product, which can be increased by offering a visualisation of the product (Dellaert and Dabholkar, 2009).

\subsection{The benefit of design automation to offer customised products}

In the case of the highly integrated products - where the customisation by rearrangement of modules is not possible - the product geometry mode, i.e. CAD, needs to be modified and rearranged for each custom configuration. CAD models, however, are inherently rigid (Heikkinen, Johansson and Elgh, 2018) and adjusting manually a CAD model to individual customer requirements (or even re-creating a new model for each customised variant) is an inefficient method for consumer products. The cost of engineering would outweigh the benefits of individual customisation.

Design Automation (DA), sometimes defined as a sub-field of Knowledge-Based Engineering (KBE) (Van der Velden et al., 2012), is an approach that uses programming and advanced CAD techniques to automate the process of CAD model modification. The general goal is to remove repetitive manual engineering activities and allows resources to be placed in creative and more value-creating activities (La Rocca and van Tooren, 2007). Most commonly this approach is pursued through a highly parameterised master-model (Sandberg et al., 2011), which can be adjusted by altering dimensional characteristics. Examples for this 
approach can be found by Amadori et al. (2012) or Heikkinen and Müller (2015). More complex approaches work with the re-combination of promotive geometries (La Rocca and van Tooren, 2007; Helms and Shea, 2012).

Most of these master-model approaches enable a fast and efficient generation and analysis of multiple alternative configurations, improving the efficiency of the product development process (Camba et al., 2016). In theory when trying to evaluate all possible combinations of multiple continuous parameters, infinite permutations are possible. One approach to achieve a reasonably good approximation of the alternatives while handling a manageable number of designs is design of experiments (DoE). In such an approach, the search space of all available parameter ranges is discretised, and specific coordinate points in this design space are simulated. Based on these results, so-called response surfaces can be created that allow the approximate the computation of arbitrary parameter combinations outside the actually simulated range. These techniques focus primarily at generating knowledge about the alternatives (supporting developers in their choice which concept to pursue) instead of generating product alternatives based on a customer choice.

If performed in such a way that all possible permutations are generated before a customer places an order, this would mean that manufacturing could begin near instantly, as the 3D file would already be generated. Beyond improving the manufacturing processes to enable customisation, developments within design techniques can be used to further increase production efficiency (La Rocca and Van tooren, 2007). Particularly, customisation is extremely demanding on the design process (Hvam, 2008) (Heikkinen and Müller, 2015). Effectively updating previous CAD models and DA are being introduced to improve the efficiency of the product development process (Camba et al., 2016).

Current approaches to DA employ largely a model-based engineering approach (Isaksson, 2003) which uses CAD software to define both individual components and product assemblies. Tools such as parametrisation are extremely powerful in model-based engineering as they have the capability to produce almost unlimited design variations from one carefully defined master model (Sandberg et al., 2011). A parameterised model is a geometry that is controlled by non-geometric features called parameters, which can be defined by dimensions, equations or logic expressions (Lokgård and Grandicki, 2017).

The design intent of the model, such as the range of customer requirements (Bertoni et al., 2013) must be carefully considered throughout the modelling process. This relies on imparting 'knowledge' to the model, in the form of values, rules and relations which control the geometry transformations of the model (Kukec, 2015). There are two distinct categories of geometry transformations that can be used within the parametric modelling space; morphological and topological transformations (Amadori et al., 2012). Topological transformations involve the locations of certain features and their occurrence, whereas morphological transformations define the form or shape of the object.

The classical route of design would involve generating ideas, defining conceptual solutions, modelling and evaluating (Isaksson, 2003). Hence, when offering customisation, each product would require re-modelling and evaluation. When using DA, it is possible to create all possible permutations of a product at once and store them in a database, removing any repetition and ultimately saving time and money.

While creating a parameterised CAD model can be more time consuming than creating a direct model initially, the repeated activities required when creating many individual designs will very quickly be offset as the model-based engineering approach requires only one set-up before DA can be utilised.

\section{A MODEL-BASED APPROACH TO DESIGN AUTOMATION OF LARGE-SCALE AM PRODUCTS}

The literature review points to the benefit of the tools and methods provided by DA for the customisation of large-scale products through AM. Therefore, this paper proposes a model-based approach to automate the design process of large-scale and integrated products. The automation of the design process creates a database of design concepts, which can be generated based on user information. The information exchange between the different stakeholders and the concept database is illustrated in Figure 1.

The database contains CAD files for different design configurations, which each corresponds to a specific customer profile. Furthermore, product information such as production cost and environmental impact (generated through AM process simulations) are available for each concept. 


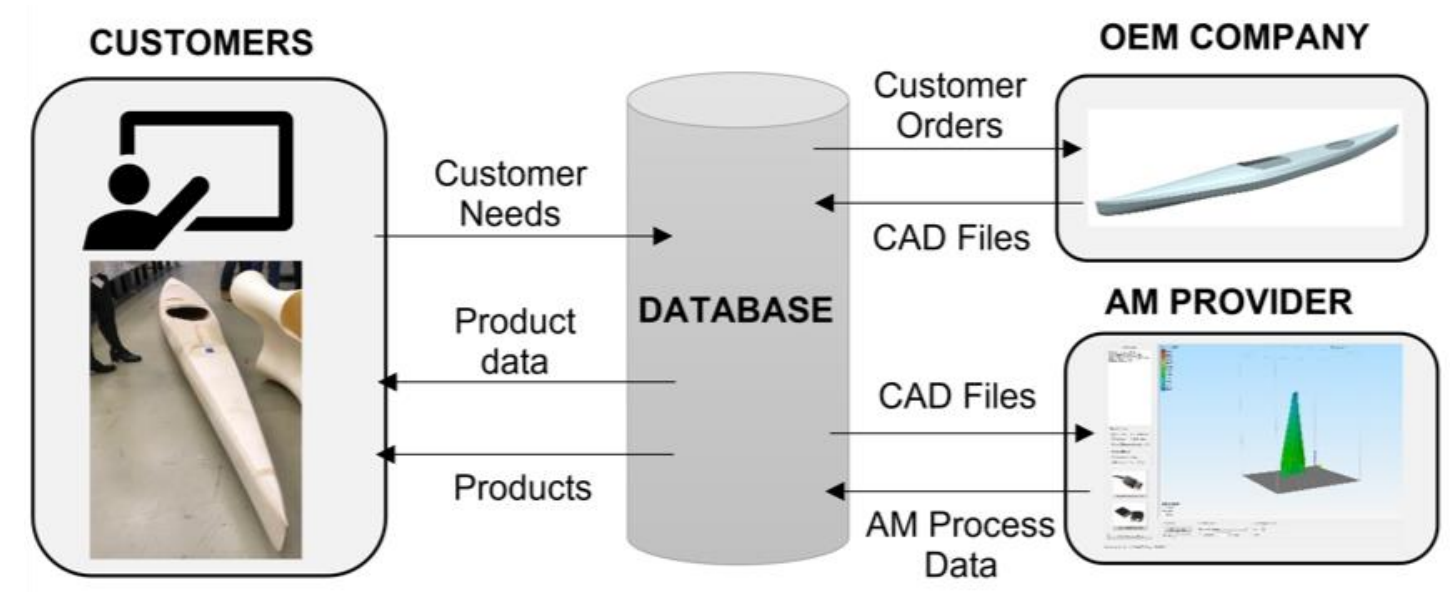

Figure 1: Information exchange between customer, OEM and AM provider

The customer profiles are generated through a prioritised ranking of customer needs and requirements, based on application and experience level. Customers interact with the information contained in the database through an intuitive visualisation contained in a user interface. This enables even non-expert customers to access the expansive concept database, and sort through the options in a comprehensible format. Customers can then place an order of their custom design to the original equipment manufacturer (OEM).

Integrating the automated design process, AM and mass customisation into one specific application with a direct interface is applied in a case study and discussed in the following chapters.

\section{APPLYING THE MODEL-BASED APPROACH TO THE CASE STUDY OF CUSTOM AM KAYAKS}

In order to demonstrate the model-based approach to design automation, a case study was defined in collaboration with the project partners related to the AM customisation of kayaks.

This case study is relevant because kayaks would benefit from increased customisation as there are many different features, types of kayaking, levels of experience and preference combinations that lead to a large range of options. Also, the new customers are likely to be non-experts of kayaking, who cannot articulate their preferences for design features in precise and measurable terms. Such customers are likely to express needs in generic terms (e.g., 'I prefer a kayak with high tracking', 'I prefer a kayak with high stability', 'I prefer a cheap kayak'). This co-design process between the customers and the designers would require a substantial amount of manual work and trial-and-error with the risk of undermining the potential of AM in terms of cost and lead times. For these reasons, the design process of customised kayaks is considered relevant for the demonstration of the benefits of a model-based and DA approach. It should be noted that Kayaks are just one of the large-scale products that could benefit from employing such a process.

The approach used within the case study can be seen in Figure 2, and consists of four principal phases:

1. Mapping customer needs to design parameters;

2. Creation of a parametric model and generate design configurations;

3. Linking design configurations to AM process simulations;

4. Visualisation of product information.

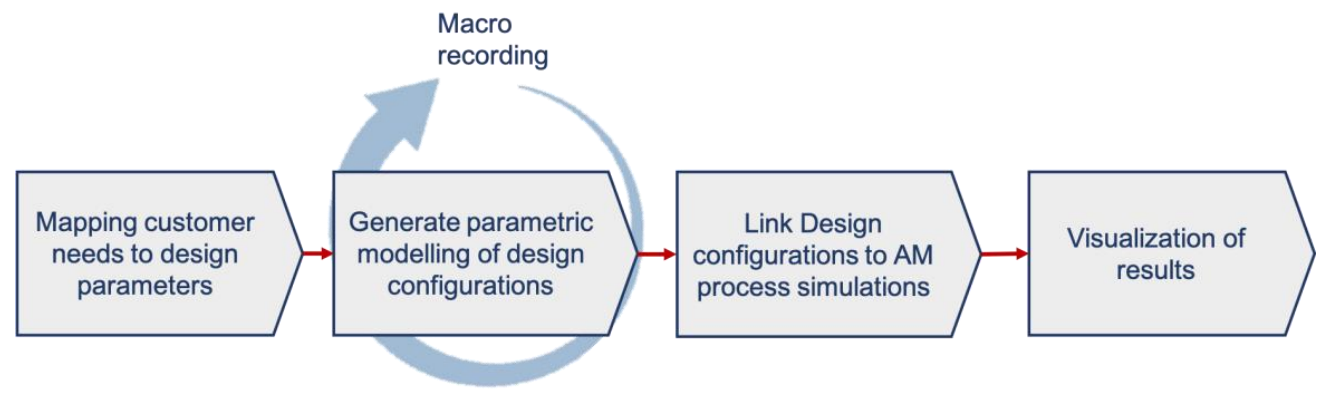

Figure 2: The applied model-based approach to large-scale AM design 
The proposed approach aims to increase the range of customisation while maintaining lead times that are suitable for the mass market.

\subsection{Mapping customer needs to design parameters}

The objective of the mapping phase is to capture the needs of kayakers and to connect them to the design parameters in the CAD model. This is an important step since novice kayak users do not know about the different trade-offs involved in kayak design, which require the expert knowledge from kayak designers as well as professional users. For example, tracking and manoeuvrability are a complex pair of features which lie at opposite ends of a spectrum, and when one is high the other must be low (Figure 3).

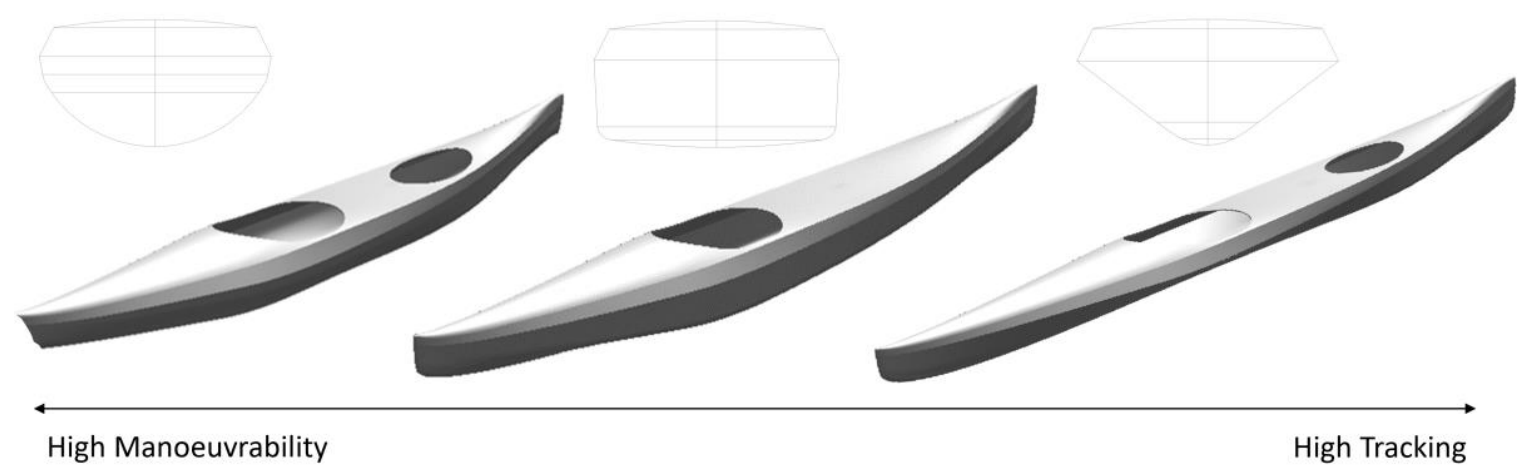

Figure 3: Selection of kayaks generated in NX to fulfil various consumer requirements

Hence, the optimal design is depending on to what extent customers prefer manoeuvrability over tracking. This is in typically depending on the type of application and the level of kayaking experience of the user. The needs and requirements integrated into the model were: waist width, leg length, storage requirements and tracking vs manoeuvrability requirements. These needs were captured using a value creation strategy (VCS) (Isaksson et al., 2003) and prioritised using pairwise comparison (Figure 4, left). Four VCS were created, based on the following scenarios: touring and recreational kayaks - suitable for sea and flat-water use - for novice through to experienced users. The initial mapping was translated into a detailed priority matrix for each of the identified scenarios. Figure 4 (left) displays the priority matrix for beginner recreational users, showing that beginner recreational kayaks would value stability, safety and a low cost.
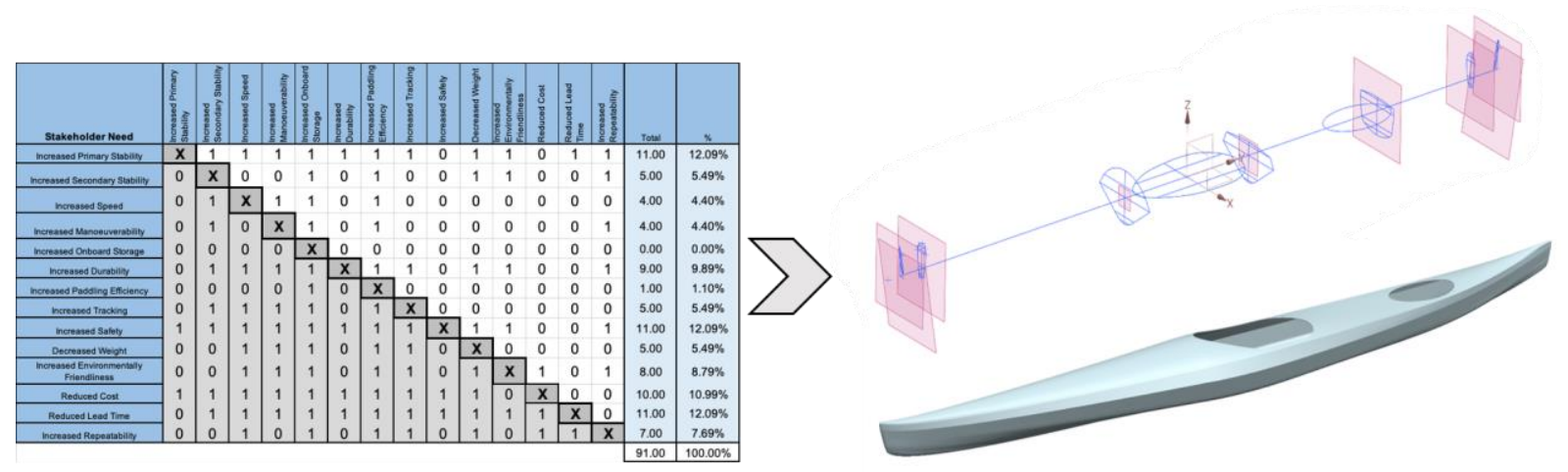

Figure 4: Priority matrix for recreational users (left), mapping of customer needs to parametric model using expressions (top right), resulting parameterised kayak (bottom right)

In the next step of this phase, the customer needs and requirements were connected to the design features and parameters of the kayak. Hence, this phase concerned on extracting design knowledge who typically is of the domain of kayak designers as well as professional users.

For example, the kayak geometry features connected to tracking and manoeuvrability are kayak length, rocker (lengthwise curvature of the kayak) and hull shape. While the length and rocker relationships are linear, the hull-shape changes between three distinct profiles which make this feature complex to integrate 
into the model. The top right of Figure 4 displays the control elements in the CAD model, and below a rendered configuration is displayed.

\subsection{Generation of parametric model for design configurations}

An off-the-shelf CAD software package was used for DA. The kayak's geometry was parameterised, and expressions governing the relationships between them were created and used to control the kayak's shape via external values stored in a spreadsheet. This was used to test the parameterisation and controlling expressions.

In order to achieve higher model flexibility, the software package's macro recording feature was utilised. This practice enables the user to automatically perform alterations in the product geometry without directly having to interact with the CAD model.

The parameterisation enabled to control of the value drivers outlined in the mapping phase. For example, Figure 4, displays how the kayak adapts to meet various consumers requirements on tracking and manoeuvrability.

\subsection{Link design configurations to AM process simulations}

This phase is related to the connection of the parametric design configurations to AM process simulations, in order to provide information about the cost and build time to the users. Kayak STEP files for three different designs (that represented the designs with lowest, average and highest volume) were sent to a local AM provider used to perform AM process simulations in a AM software, ABB Robot Studio®. The data received from the AM simulations were then used to generate scaling rules (Langmaak et al., 2013), to provide input data for the cost model (Rickenbacher et al, 2013) and the carbon dioxide model (le Bourhis et al., 2014). One example of such scaling rules is the relationship between the print volume (from CAD file) and build time. This did constrain the design space but was intended to, ensuring the kayak stayed within limits and relationships defined in the parametric model were maintained.

Hence, the data obtained from ABB Robot Studio® used to populate the scaling rules were used as 'surrogate models' which in turn was fed into the cost and carbon dioxide models for each respective design. It should be noted that only electric consumption was considered in the carbon dioxide model. In this case, the role of the AM provider was taken by a Swedish Research Institute. In an actual business scenario, this role can be taken by multiple AM providers close to the customer location.

\subsection{Visualisation of product information}

Based on the developed models and the data coming from process simulations, a visual user interface (UI) for kayak configuration was built. After selecting the anthropometric measurements and preferences as well as the level of experience from the user, a kayak concept is configured from the database (Figure 5). The UI presented this concept showing:

- An image of the kayak, to give a more tangible product;

- Overall price, with a graph showing a breakdown so the consumer can see where their money is being spent;

- Resulting carbon emissions, as people are becoming more aware of their own environmental impact;

- Delivery time, which allows the user to not only see the overall time but how long each section of the process is taking giving a greater level of transparency.

The completed user interface can be seen below in Figure 5. It was created in two different layouts, for both beginner and advanced kayak customers (e.g., professionals). 


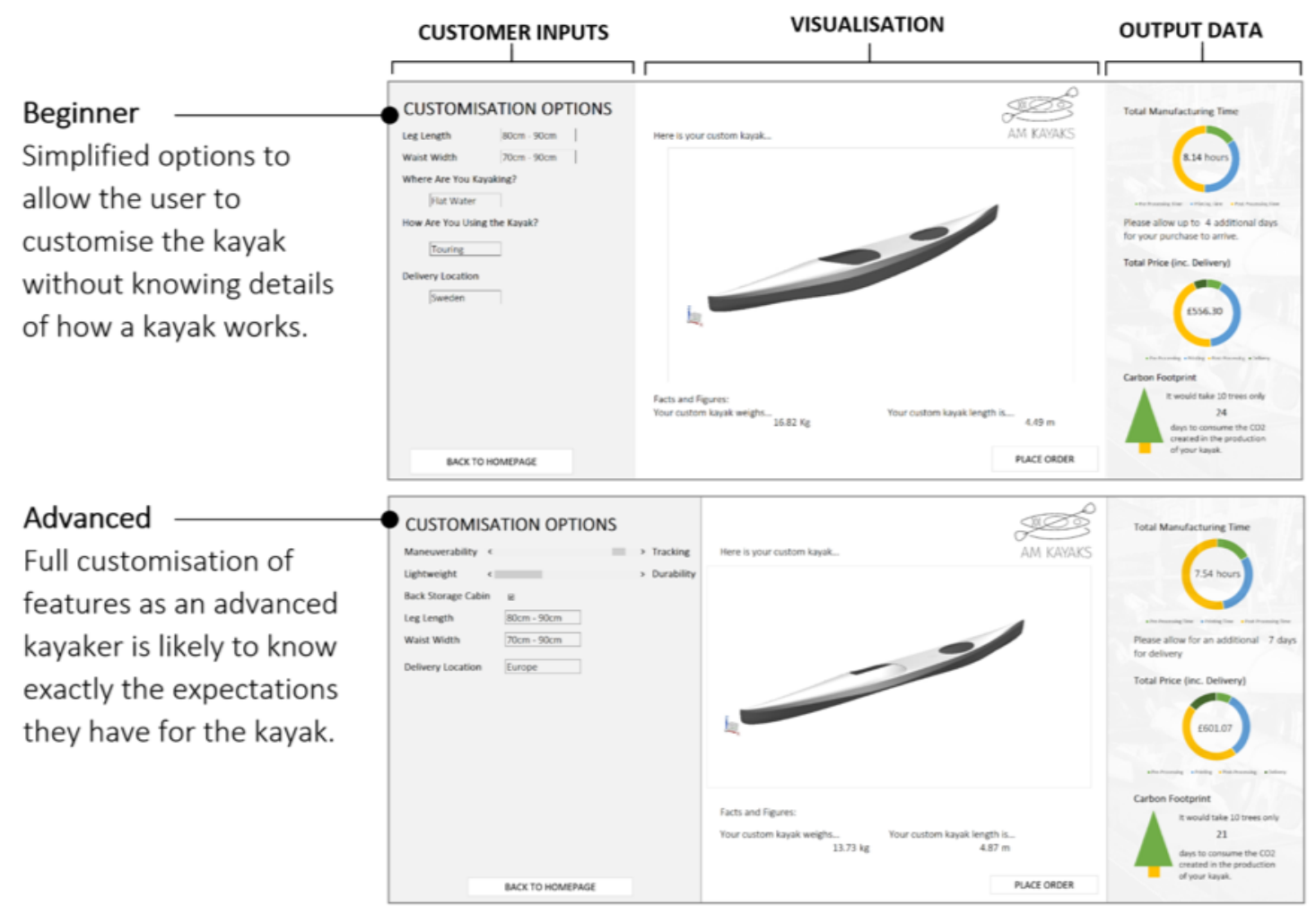

Figure 5: User Interface for beginner and advanced kayaking customers

To reference the database from the UI, the approach taken was to generate unique cell identifier (ID). The cell ID was a combined string of all the different input parameters that went into the CAD model. This allowed communication between the interface and database to be simplified and made more efficient.

\section{DISCUSSION}

Current applications for DA (Lokgård and Grandicki, 2017) rely on the careful definition of a master model (La Rocca et al., 2007) that automatically links different models, so that the design activity does not involve unnecessary product definition tasks. A number of applications for DA (e.g., Sandberg et al., 2011) have linked models related to engineering and technical aspects of product behaviour such as cost, weight, manufacturing, aerodynamics. This paper has elaborated on these studies but has further focused on enhancing a 'master model' by linking customer needs and preferences for the product (such as manoeuvrability, stability, tracking, safety) to geometric properties. This is important to foster mass customization of large-scale products using additive manufacturing. In this context, new customers are likely to be non-experts who typically do not express their needs and expectations in the form of engineering requirements and geometrical features. At the same time, novice kayak users do not know about the different trade-offs involved in kayak design. Utilising DA in conjunction with model-based engineering enables the matching of design knowledge and user expertise to provide an individually customized product. Thus, the model-based approach presented in this paper supports the needs reflected by the users and the companies involved in the project. This can be seen as a logical verification of the approach (Buur, 1990).

The presented approach has the potential to save considerable design effort, increasing the efficiency of the process and thereby allowing valuable resources to be placed elsewhere. To make a comparison, the overall time taken to automatically generate the 594 permutations and all the associated data was approximately 20 hours. Having consulted a designer of customised kayaks, it is estimated that in the same timeframe, a human designer could generate a maximum of 40 permutations which demonstrates a factor fifteen increase in efficiency. However, the time spent to set up the model-based approach (approximately two months) should be included in this measurement for efficiency to make a fair comparison.

Nevertheless, the time and resources invested in developing the approach should be compared against the benefits of the approach in the long run, which may not be directly measurable as time savings. In this research, this was done by presenting the approach to the project partners. Feedback gathered from the 
professional stakeholders in a validation exercise was positive acknowledging that for small series production, this is perfect' and that there is additional importance as it 'offers 'the possibility of a digital value chain'. This can be seen as a 'verification by acceptance' (Buur, 1990). However, further work has to be done to validate and generalize the presented approach.

\section{CONCLUSIONS AND FUTURE WORK}

In this paper, a model-based approach has been presented to support mass customisation of AM-produced products. The study showed decreased lead-times from ordering up to production, by combining design and expert user knowledge in a DA approach. This is important for manufacturers of large-scale products (such as kayak manufacturers), who are interested in using AM to increase customisation. These new customers are likely to be non-experts who find it difficult to articulate their needs and expectations in the form of precise and measurable design requirements and features.

Through a visual UI, users without expertise in neither the product nor the design process can generate a customised product tailored to their specific needs. Therefore, this method can be seen as an enabler to AM by reducing the otherwise necessary long design process, which undermines the expected benefits of AM in terms of cost efficiency and short lead times. To achieve this, different DA techniques were combined, such as parameterisation and surrogate models.

Future work will focus on dealing with the limitations of the present study. In the presented kayak case, there was a logical and direct mapping between needs, functions and geometries. Future work will focus on generalising the approach to other products where the logic of this mapping is more articulated. Also, the present study has not focused on actually printing the kayaks generated from the database to verify their functionality, stiffness, reliability and surface finish. Current activities are ongoing, in collaboration with another research institute. Future work will focus on assessing the differences between the kayaks 3D printed (generated through the DA approach) and the kayaks made through traditional processes (e.g. rotational moulding).

\section{REFERENCES}

Amadori, K., Tarkian, M., Olvander, J. and Krus, P. (2012), "Flexible and robust CAD models for design automation", Advanced Engineering Informatics, Vol. 26 No. 2, pp. 180-195. https://doi.org/10.1016/j.aei.2012.01.004

Avison, D., Lau, F., Myers, M., Nielsen, P.A. (1999), “Action Research”, Communications of the ACM, Vol. 42 No. 1 , pp. 94-97, https://doi.org/10.1145/291469.291479

Bertoni, M., Bertoni, B., Isaksson, O., Amnell, H. and Johnsson, C. (2013), "Value-oriented concept selection in aeroengine sub-systems design: The EVOKE approach,” 23rd Annual INCOSE International Symposium, Vol. 23 No. 1, pp. 770-784, https://doi.org/10.1002/j.2334-5837.2013.tb03053.x

Buur, J. (1990), A Theoretical Approach to Mechatronics Design, Doctoral Dissertation, Institute for Engineering Design, Technical University of Denmark, Lyngby, Denmark.

Borgue, O., Müller, J., Panarotto, M. and Isaksson, O. (2018), "Function modelling and constraints replacement to support design for additive manufacturing of satellite components". DS 91: Proceedings of NordDesign 2018, Linköping, Sweden, 14th-17th August 2018.

Camba, J. D., Contero, M. and Company, P. (2016), "Parametric CAD modeling: An analysis of strategies for design reusability," Computer-Aided Design, Vol. 74 No. 1, pp. 18-31, https://doi.org/10.1016/j.addma.2014.08.005

Campbell, R. I., Bourell, D. and Gibson, I. (2012), “Additive manufacturing: rapid prototyping comes of age”, Rapid prototyping journal, Vol. 18 No. 4, pp. 255-258. https://doi.org/10.1108/13552541211231563

Dellaert, B.G.C. and Dabholkar, P.A. (2009), " Increasing the Attractiveness of Mass Customization: The Role of Complementary On-line Services and Range of Options," International Journal of Electronic Commerce, Vol. 13 No. 3, pp. 43-70. https://doi.org/10.2753/JEC1086-4415130302

Franke, N. and Piller, F.T. (2003), "Key Research Issues in User Interaction with Configuration Toolkits in a Mass Customization System", The International Journal of Technology Management, Vol. 26 No. 5/6, pp. 578-599.z

Heikkinen, T. and Müller, J. (2015), Multidisciplinary analysis of jet engine components: Development of methods and tools for design automatisation in a multidisciplinary context, Master Thesis, Jönköping University.

Heikkinen, T., Johansson, J. and Elgh, F. (2018), "Review of CAD-model capabilities and restrictions for multidisciplinary use", Computer-Aided Design and Applications, Vol. 4360 No. January, pp. 1-11. https://doi.org/10.1080/16864360.2017.1419639

Helms, B. and Shea, K. (2012), "Computational Synthesis of Product Architectures Based on Object-Oriented Graph Grammars", Journal of Mechanical Design, Vol. 134 No. 2, p. 021008. https://doi.org/10.1115/1.4005592

Hvam, L., Mortensenm N.H. and Riis, J. (2008), Product Customization, Springer, Berlin.

Isaksson, O. (2013), “A Generative Modeling Approach to Engineering Design”, International Conference on Engineering Design, Stockholm, August 19-21. 
Isaksson, O., Kossmann, M., Bertoni, M., Eres, H., Monceaux, A., Bertoni, A. and Zhang, X. (2013), "Value-Driven Design-A methodology to Link Expectations to Technical Requirements in the Extended Enterprise", INCOSE International Symposium, Vol. 23 No. 1, pp. 803-819. https://doi.org/10.1002/j.2334-5837.2013.tb03055.x

Kukec, G. (2015), "Decreasing Engineering Time with Variable CAD Models: Parametric Approach to Process Optimisation," Computer-Aided Design and Applications, Vol. 12 No. 5, pp. 651-661. https://doi.org/10.1080/16864360.2015.1014744

La Rocca, G. and Van tooren, M. (2007), "Enabling distributed multi-disciplinary design of complex products: a knowledge based engineering approach", Journal of Design Research, Vol. 5 No. 3 pp. 333-352. https://doi.org/10.1504/JDR.2007.014880

Langmaak, S., Wiseall, S., Bru, C., Adkins, R., Scanlan, J. and Sobester, A. (2013), “An activity-based-parametric hybrid cost model to estimate the unit cost of a novel gas turbine component", International Journal of Production Economics, Vol. 142 No. 1, pp. 74-88. https://doi.org/10.1016/j.ijpe.2012.09.020

Le Bourhis, F., Kerbrat, O., Dembinski, L., Hascoet, J.Y. and Mognol, P. (2014), "Predictive model for environmental assessment in additive manufacturing process". Procedia CiRP, Vol. 15, pp.26-31.

Lindwall, A., Dordlofva, C. and Öhrwall Rönnbäck, A. (2017), “Additive manufacturing and the product development process: Insights from the space industry”, 21st International Conference on Engineering Design, ICED 2017, Vol. 5 No. DS87-5, pp. 345-354.

Lokgård, M. and Grandicki, A. (2017), Parametric CAD Modelling to Aid Simulation-Driven Design, Master Thesis, Linköping University, Sweden.

Mcutcheon, D.M., Raturi, A.S. and Meredith, J.R. (1994), “The Customisation-Responsiveness Squeeze”, Sloan Management Review, Vol. 35 No. 2, pp. 89-99.

Panarotto, M. (2015). A Model-Based Methodology for Value Assessment in Conceptual Design. Doctoral dissertation, Blekinge Institute of Technology (Blekinge Tekniska Högskola), Sweden.

Prahalad, C.K. and Ramaswamy, V. (2004), "Co-Creation Experiences: The Next Practise in Value Creation", Journal of Interactive Marketing, Vol. 18 No.3, pp. 5-14. https://doi.org/10.1002/dir.20015

Reeves, R., Tuck, C. and Hauge, R. (2011), “Additive Manufacturing for Mass Customisation,” In: Fogliatto, F.S. and Da Silveria G.J.C., Mass Customisation: Engineering and Managing Global Operations, pp. 274-289.

Rickenbacher, L., Spierings, A., Wegener, K. (2013), "An integrated cost-model for selective laser melting (SLM)", Rapid Prototyping Journal, Vol. 19 No. 3, pp.208-214. https://doi.org/10.1108/13552541311312201

Roth, M., Ulrich, C. M., Holle, M. and Lindemann, U. (2016). "The impact of user-driven customization on the development process", Proceedings of International Design Conference, DESIGN, DS, Vol. 84, pp. 1357-1366.

Sandberg, M., Tyapin, I., Kokkolaras, M., Isaksson, O., Aidanpää, J. and Larsson, T. (2011), “A Knowledge-based Master-model Approach with Application to Rotating Machinery Design," CONCURRENT ENGINEERING: Research and Applications, Vol. 19 No. 4, pp. 295-305. https://doi.org/10.1177/1063293X11424511

Spallek, J. and Krause, D. (2016), "Process types of customisation and personalisation in design for additive manufacturing applied to vascular models", 26th CIRP Design Conference, Stockholm, 15-17 June, Elsevier, pp. 281-286, https://doi.org/10.15480/882.1907

Thompson, M. K. et al. (2016), "Design for Additive Manufacturing: Trends, opportunities, considerations, and constraints", CIRP Annals - Manufacturing Technology, Vol. 65 No. 2, pp. 737-760. https://doi.org/10.1016/j.cirp.2016.05.004

Ulrich, K., Eppinger, S. (2011), Product design and development (5th edition). McGraw-Hill, New York

Van der Velden, C. A., Bil, C. and Xu, X. (2012), "Adaptable methodology for automation application development", Advanced Engineering Informatics. Elsevier Ltd, Vol. 26 No. 2, pp. 231-250. https://doi.org/10.1016/j.aei.2012.02.007

\section{ACKNOWLEDGMENTS}

We would like to express our greatest thanks to all participants of the DiLAM project (Digitalized Large Scale Additive Manufacturing) for contributing to this study. In addition, the financial support from Vinnova, the Swedish Governmental Agency for Innovation Systems, is gratefully acknowledged. 